\title{
KUALITAS PELAYANAN DAMPAKNYA TERHADAP KEPUASAN DAN LOYALITAS PASIEN RUMAH SAKIT MUHAMMADIYAH PALEMBANG
}

\author{
Maftuhah Nurrahmi, Hardiansyah Al-Fikri \\ Fakultas Ekonomi dan Bisnis Universitas Muhammadiyah Palembang \\ JL. A. Yani 13 Ulu Palembang
}

\begin{abstract}
This research is formulated whether or not there was significant influence of service quality toward the patients' satisfaction and loyality impact at mauhammadiyah hospital Palembang. This research was aimed at determining the significant influence of service quality toward the patients' satisfaction and loyality impact at muhammadiyah hospital Palembang. This research type was such an associative. The research location was at muhammadiyah hospital of Palembang. There were 100 respondents used as sample of the research. The data sources were primary data and secondary data. To collect the data, the researcher used questionnaire. To analyze the data, the researcher used Structural Equation Model (SEM) for windows 8.70 version. The resuls showed that there was significant of service quality toward the patients' satisfaction and loyality impact at muhammadiyah hospital Palembang.
\end{abstract}

Keywords : service quality, patients' satisfaction, loyality

Correspondence to : umiulul@gmail.com, ikhwanperindu@gmail.com

\begin{abstract}
ABSTRAK
Rumusan masalah dalam penelitian ini yaitu 1) adakah pengaruh kualitas pelayanan terhadap kepuasan pasien Rumah Sakit Muhamadiyah Palembang. 2) Adakah pengaruh kepuasan pasien terhadap loyalitas pasien Rumah Sakit Muhammadiyah Palembang. Tujuan penelitian ini 1) Untuk mengetahui pengaruh kualitas pelayanan terhadap kepuasan pasien Rumah Sakit Muhamadiyah Palembang. 2) Untuk mengetahui pengaruh kepuasan pasien terhadap loyalitas pasien Rumah Sakit Muhammadiyah Palembang. Jenis penelitian ini adalah asosiatif dengan tempat penelitian di rumah sakit Muhammadiyah Palembang. Penelitian ini menggunakan sampel sebanyak 100 responden. Data yang digunakan adalah primer dan sekunder, sedangkan teknik pengumpulan datanya adalah kuesioner. Adapun teknik analisis data yang dugunakan adalah Structural Equation Modelling (SEM) for windows versi 8.70. Hasil penelitian menujukkan bahwa 1) Kualitas pelayanan berpengaruh positif signifikan terhadap kepuasan pasien rumah sakit Muhammadiyah Palembang. 2) kepuasan pasien berpengaruh positif signifikan terhadap loyalitas pasien rumah sakit Muhammadiyah Palembang.

Kata Kunci $\quad$ : Kualitas Pelayanan, Kepuasan Pasien, Loyalitas Pasein.

Korespondensi : $\underline{\text { umiulul@gmail.com, ikhwanperindu@gmail.com }}$
\end{abstract}

PENDAHULUAN / INTRODUCTION

Pada era globalisasi ini, peningkatan

kualitas jasa yang akan ditawarkan semakin banyak mendapatkan perhatian bagi perusahaan. Hal ini disebabkan karena kualitas jasa dapat digunakan sebagai alat 
untuk mencapai keunggulan yang kompetitif. Adanya peningkatan kualitas jasa yang baik dapat menimbulkan kepuasan dan loyalitas jasa yang dirasakan oleh konsumen baru. Konsumen yang loyal terhadap suatu produk atau jasa dapat diartikan bahwa konsumen tersebut merasa terpuaskan kebutuhannya, sehingga cenderung kemungkinan besar dapat menarik konsumen baru dan melakukan pembelian lebih dari sekali. Dengan konsumen melakukan pembelian lebih dari sekali maka perusahaan akan mendapatkan keuntungan dari konsumen tersebut. Sering terdapat perbedaan antara harapan dengan persepsi konsumen terhadap kualitas pelayanan yang diberikan oleh perusahaan.

Kualitas pelayanan (service quality) adalah ukuran sejauh mana suatu pelayanan yang diberikan dapat memenuhi harapan pelanggan (Kotler \& Keller, 2009:143). Menurut Zeuthaml dalam Fandy Tjiptono (2008:27) Dalam mengevaluasi kepuasan terhadap kualitas jasa atau perusahaan tertentu, umumnya konsumen mengacu pada beberapa faktor atau dimensi. Terdapat lima dimensi kualitas jasa kesehatan yang umumnya di nilai oleh konsumen antara lain : (1) Keandalan, yaitu seperti janji ditepati sesuai jadwal dan diagnosisnya terbukti akurat. (2) daya Tanggap, yaitu seperti tidak lama menunggu, mudah diakses dan bersedia mendengar keluh kesah pasien. (3) Jaminan, yaitu meliputi keterampilan, pengetahuan kepercayaan dan reputasi. (4) Empati, yaitu seperti mengenal pasien dengan baik mengingat masalah penyakit dan lain-lain. (5) Bukti Langsung, yaitu meliputi ruang tunggu, ruang operasi peralatan dan bahanbahan tertulis.

Kepuasan konsumen adalah perasaan senang atau kecewa seorang yang timbul karena membandingkan kinerja yang dipersepsikan produk atau jasa terhadap hasil ekspektasi mereka (Kotler \& Keller,
2009:139). Kepuasan konsumen hanya dapat tercapai dengan memberikan pelayanan yang berkualitas kepada konsumennya. Pelayanan yang baik sering dinilai oleh konsumen secara langsung dari karyawan sebagai orang yang melayani, karena itu diperlukan usaha untuk meningkatkan kualitas pelayanan yang diberikan agar dapat memenuhi keinginan dan meningkatkan kepuasan konsumen.

Implementasi kualitas jasa yang dilakukan oleh suatu perusahaan yang bergerak dibidang kesehatan adalah dengan memberikan kualitas pelayanan yang baik bagi konsumen dengan tujuan menciptakan kepuasan konsumen sehingga menimbulkan suatu sikap loyalitas.

Menurut Oliver dalam buku Ratih Hurriyati (2009:129) Loyalitas pelanggan adalah komitmen pelanggan bertahan secara mendalam untuk berlangganan kembali atau melakukan pembelian ulang produk/jasa terpilih secara konsisten dimasa yang akan datang, meskipun pengaruh situasi dan usaha-usaha pemasaran mempunyai potensi untuk menyebabkan perubahan perilaku.

Penelitian sebelumnya yang dilakukan oleh Habibaturrahmah dan Diah Isnaini Asiati (2011) dan M. Rofik (2015) juga menunjukkan bahwa kualitas pelayanan memiliki pengaruh positif signifikan terhadap kepuasan pasien rumah sakit Muhammadiyah Palembang.

Menentukan kualitas pelayanan terhadap kepuasan pelanggan, pada perusahaan manufaktur dapat diketahui secara nyata karena memproduksi barang yang berwujud, sedangkan pada perusahaan jasa akan sulit diukur kualitas dan kepuasannya. Salah satu contoh perusahaan jasa adalah Rumah Sakit yang bergerak dalam bidang kesehatan.

Rumah sakit sebagai institusi yang bergerak dibidang pelayanan kesehatan mengalami perubahan. Ada awal perkembangannya, rumah sakit adalah 
lembaga yang berfungsi sosial. Akan tetapi dengan adanya rumah sakit swasta, menjadi rumah sakit lebih mengacu sebagai suatu industri yang bergerakdalam bidang pelayanan kesehatan, dengan melakukan pengelolaan yang berdasarkan pada manajemen badan usaha. Seiring dengan itu, terjadi persaingan antara sesama rumah sakit baik rumah sakit milik pemerintah maupun rumah sakit milik swasta, semua berlombalomba untuk menarik konsumen agar menggunakan jasanya. Hal ini menyebabkan setiap Rumah Sakit harus menempatkan orientasi pada kepuasan pelanggan sebagai tujuan utamanya.

Rumah Sakit Muhammadiyah Palembang adalah Amal Usaha Persyarikatan Muhammadiyah, yang diresmikan tanggal 10 Dzulhijjah 1417 H / 18 April 1997 oleh Gubernur Propinsi Sumatera Selatan (Bapak H. Ramli Hasan Basri) bersama Ketua PP Muhammadiyah (Bapak Prof. DR. Amien Rais). Rumah Sakit Muhammadiyah
Palembang merupakan satu-satunya amal usaha dibawah langsung Pimpinan Wilayah Muhammadiyah Sumatera Selatan. Rumah Sakit Muhammadiyah Palembang merupakan salah satu rumah sakit swasta golongan $\mathrm{C}$ yang ada di kota Palembang

Pada bulan Febuari 2017 peneliti melakukan riset pendahuluan dengan melakukan wawancara langsung terhadap para pasien di Rumah Sakit Muhammadiyah Palembang. Yang berjumlah 30 orang. Dalam wawancara tersebut menanyakan kepada pasien terkait pendapat dan keluhan mengenai pelayanan yang diberikan oleh Rumah Sakit Muhammadiyah Palembang. Dari hasil wawancara tersebut masih banyak pasien Rumah Sakit Muhammadiyah Palembang yang menyatakan belum sepenuhnya terpuaskan atas pelayanan yang diberikan oleh Rumah Sakit Muhammadiyah Palembang.

Tabel 1

Pendapat pasien terhadap pelayanan Rumah Sakit Muhammadiyah Palembang

\begin{tabular}{|c|c|c|}
\hline No. & Indikator & Jumlah pasien \\
\hline 1. & Kurang baik pada pelayanan & 5 orang \\
\hline 2. & Proses administrasi lambat & 6 orang \\
\hline 3. & Pelayanan baik & 3 orang \\
\hline 4. & Petugas keamanan yang agresif & 8 orang \\
\hline \multirow[t]{2}{*}{5.} & Keramahan perawat kurang & 8 orang \\
\hline & Jumlah & 30 orang \\
\hline
\end{tabular}

Sumber : Hasil wawancara, 2017

Tabel 1 menunjukkan bahwa pelayanan pada rumah sakit Muhammadiyah Palembang kurang baik, hal ini dapat dilihat dari pernyataan pasien sebanyak $16,6 \%$ orang yang mengatakan hal tersebut. Sebanyak $20 \%$ pasien menyatakan proses administrasi lambat. Pasien menyatakan pelayanan baik sebanyak $10 \%$ orang. Petugas keamanan yang agresif pada pasien dan keluarga yang

sedang berkunjung sebanyak $26,7 \%$ orang. Sedangkan pasien yang menyatakan keramahan perawat kurang sebanyak $26,7 \%$ orang.

Berdasarkan tabel wawancara diatas tampaknya respon pasien memberikan penilaian yang relatif sama dalam pernyataannya ialah tidak puas mengenai pelayanan di Rumah Sakit Muhammadiyah 
Palembang. Hal ini ditunjukan oleh berbagai pendapat yang bersifat kurang baik, bahkan hanya ada tiga pasien yang pendapatnya tentang Rumah Sakit Muhammadiyah palembang baik.

\section{Tujuan penelitian}

Berdasarkan masalah yang dikemukakan diatas maka tujuan dari penelitian ini adalah :

1. Untuk mengetahui pengaruh kualitas pelayanan terhadap kepuasan pasien Rumah Sakit Muhamadiyah Palembang.

2. Untuk mengetahui pengaruh kepuasan pasien terhadap loyalitas pasien Rumah Sakit Muhammadiyah Palembang.

\section{Hipotesis}

1. Adanya pengaruh kualitas pelayanan terhadap kepuasan pasien Rumah Sakit Muhamadiyah Palembang.

2. Adanya pengaruh Kepuasan pasien terhadap loyalitas pasien Rumah Sakit Muhammadiyah Palembang.

\section{METODE PENELITIAN / METHODS Jenis penelitian}

Jenis penelitian yang akan digunakan peneliti adalah penelitian asosiatif yaitu mengetahui pengaruh kualitas pelayanan terhadap kepuasan pasien dan dampaknya pada loyalitas pasien rumah sakit Muhammadiyah Palembang.

Penelitian ini dilakukan di rumah sakit Muhammadiyah Palembang yang beralamat di jalan jenderal ahmad yani 13 Ulu Palembang, 30263. Phone: 0711-511446, Fax 0711-519988. E-mail: contact@rsmp.co.id.

\section{Definisi Operasional dan indikator}

Tabel 2

Variabel, Sub Variabel, Definisi Variabel, Indikator dan Skala

\begin{tabular}{|c|c|c|c|c|}
\hline Variabel & $\begin{array}{c}\text { Sub } \\
\text { variabel }\end{array}$ & Define variabel & Indikator & Skala \\
\hline \multirow[t]{4}{*}{$\begin{array}{l}\text { Kualitas } \\
\text { pelayanan } \\
(\mathrm{X})\end{array}$} & $\begin{array}{l}\text { Bukti Fisik } \\
\left(\mathrm{X}_{1}\right)\end{array}$ & $\begin{array}{l}\text { Daya tarik fasilitas, fisik, perlengkapan dan } \\
\text { peralatan fisik yang digunakan serta penampilan } \\
\text { karyawan rumah sakit Muhammadiyah } \\
\text { Palembang. }\end{array}$ & $\begin{array}{l}\text { - Ruang tunggu } \\
\text { - Peralatan }\end{array}$ & Ordinal \\
\hline & $\begin{array}{l}\text { Kehandalan } \\
\left(\mathrm{X}_{2}\right)\end{array}$ & $\begin{array}{l}\text { Kemampuan rumah sakit untuk memberikan } \\
\text { pelayanan yang akurat sejak pertama kali tanpa } \\
\text { membuat kesalahan apapun dalam } \\
\text { menyampaikan jasanya sesuai dengan waktu } \\
\text { keberangkatan yang disepakati dan } \\
\text { kenyamananan yang diberikan rumah sakit } \\
\text { Muhammadiyah Palembang. }\end{array}$ & $\begin{array}{l}\text {-Diagnosis } \\
\text { akurat } \\
\text { - Janji }\end{array}$ & Ordinal \\
\hline & $\begin{array}{l}\text { Daya } \\
\text { tanggap } \\
\left(\mathrm{X}_{3}\right)\end{array}$ & $\begin{array}{l}\text { Kesedian dan kemampuan para karyawan } \\
\text { rumah sakit Muhammadiyah palembang untuk } \\
\text { membantu para pelanggan dan merespon } \\
\text { permintaan mereka, serta menginformasikan } \\
\text { kapan jasa akan diberikan dan kemudian } \\
\text { memberikan jasa pelayanan secara cepat dan } \\
\text { tepat. }\end{array}$ & $\begin{array}{l}\text {--Pelayanan } \\
\text {-Informasi }\end{array}$ & Ordinal \\
\hline & $\begin{array}{l}\text { Jaminan } \\
\left(\mathrm{X}_{4}\right)\end{array}$ & $\begin{array}{l}\text { Perilaku karyawan rumah sakit muhammadiyah } \\
\text { palembang menumbuhkan kepercayaan } \\
\text { terhadap perusahaan dapat menciptakan rasa } \\
\text { aman, serta sopan santun, pengetahuan dan } \\
\text { keterampilan yang dibutuhkan untuk menangani } \\
\text { setiap pertanyaan pelanggan. }\end{array}$ & $\begin{array}{l}\text {-Kesopanan } \\
\text {-Kepercayaan }\end{array}$ & Ordinal \\
\hline
\end{tabular}


Balance Vol. XV No. 2 | Juli 2018

\begin{tabular}{|c|c|c|c|c|}
\hline & $\begin{array}{l}\text { Empati } \\
\left(\mathrm{X}_{5}\right)\end{array}$ & $\begin{array}{l}\text { Memahami masalah pelanggan dan bertindak } \\
\text { demi kepentingan pasien, memberikan } \\
\text { perhatian secara pribadi, memiliki jam kerja } \\
\text { yang nyaman, dan keramahan dalam } \\
\text { menyampaikan informasi. }\end{array}$ & $\begin{array}{l}\text { Sabar } \\
\text {-Perhatian }\end{array}$ & Ordinal \\
\hline $\begin{array}{l}\text { Kepuasan } \\
\text { pelanggan } \\
\left(\mathrm{Y}_{1}\right)\end{array}$ & & $\begin{array}{l}\text { Respon pasien rumah sakit muhammadiyah } \\
\text { palembang terhadap evaluasi ketidaksesuaian } \\
\text { (disconfirmation) yang dirasakan antara harapan } \\
\text { sebelumnya (norma kinerja lainnya) dan kinerja } \\
\text { 64actual produk atau jasa yang dirasakan } \\
\text { setelah pemakaian }\end{array}$ & $\begin{array}{l}\text { - Fasilitas } \\
\text {-Dokter spesialis } \\
\text { - cepat tanggap. } \\
\text { - professional. } \\
\text { - mendengarkan } \\
\text { keluhan }\end{array}$ & Ordinal \\
\hline $\begin{array}{l}\text { Loyalitas } \\
\text { pelanggan } \\
\qquad\left(\mathrm{Y}_{2}\right)\end{array}$ & & $\begin{array}{l}\text { komitmen pasien bertahan secara mendalam } \\
\text { untuk berlangganan kembali atau melakukan } \\
\text { berobat ulang di RS Muhammadiyah PLG } \\
\text { secara konsisten dimasa yang akan datang, } \\
\text { meskipun pengaruh situasi dan usaha-usaha } \\
\text { pemasaran mempunyai potensi untuk } \\
\text { menyebabkan perubahan perilaku. }\end{array}$ & $\begin{array}{l}\text { - Selalu berobat } \\
\text { di RSM } \\
\text { Palembang } \\
\text {-Rekomendasi } \\
\text {-Menolak ke } \\
\text { tempat lain }\end{array}$ & Ordinal \\
\hline
\end{tabular}

Sumber : Gagasan peneliti berdasarkan teori, 2017

Teknik Pengumpulan Data

Penelitian ini menggunakan metode kuesioner, dimana kuesioner tersebut berisi pertanyaan-pertanyaan mengenai indikator dari kualitas pelayanan, kepuasan pasien atau loyalitas pasien Rumah Sakit Muhammadiyah Palembang.

\section{Analisis Data}

Analisis data menggunakan analisis kualitatif dan kuantitatif. Teknik analisis yang digunakan adalah structural equation model
(SEM) versi 8.70. Untuk menguji hipotesis yaitu pengaruh kualitas pelayanan terhadap kepuasan pasien dan dampaknya pada loyalitas pasien rumah sakit Muhammadiyah Palembang dengan model persamaan struktural dengan mengunakan bantuan perangkat lunak LISREL (linear structural relation).

HASIL PENELITIAN / RESULTS Uji Validitas Kualitas Pelayanan 


\section{Gambar 1}

Pengujian Loading Factor Kualitas Pelayanan (X)

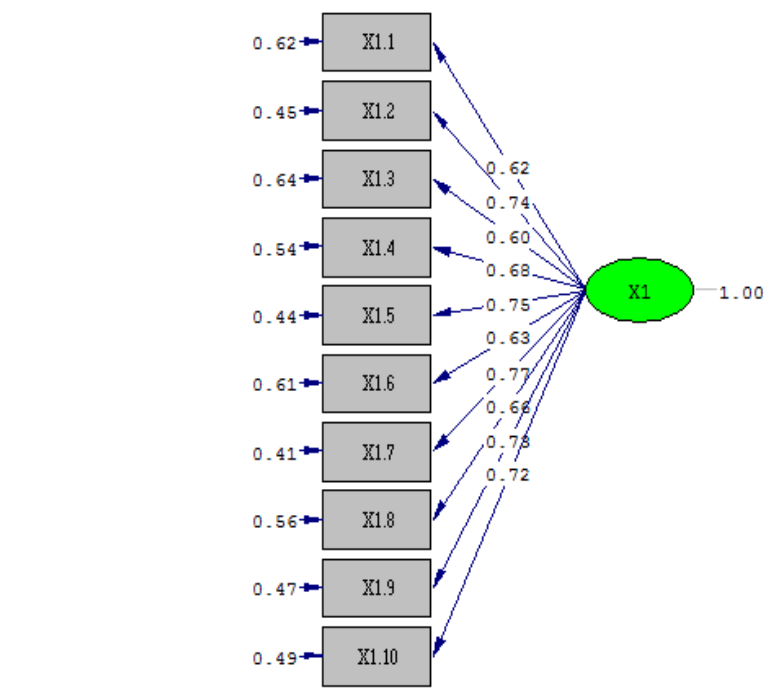

Chi-Square $=95.33, \mathrm{df}=35, \mathrm{P}$-value $=0.00000, \mathrm{RMSEA}=0.132$

Variabel kualitas pelayanan (X) diukur dengan 10 indikator pertanyaan yaitu X1_1 sampai dengan X1_10. Berdasarkan Gambar , dapat diketahui bahwa dari hasil pengujian loading factor menunjukkan bahwa X1_1 sampai X1_10 memiliki nilai loading factor $>0,5$ dengan demikian indikator tersebut valid.

\section{Uji Validitas Kepuasan Pasien (Y1)}

Gambar 2

Pengujian Loading Factor Kepuasan Pasien (Y1)

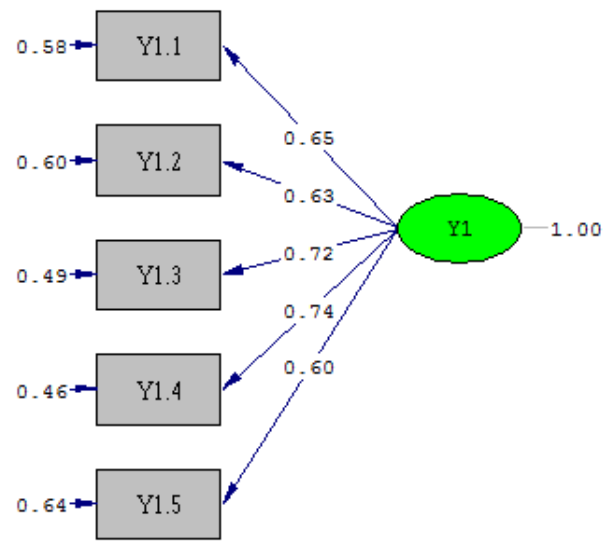

Chi-Square=1.11, df=5, P-value=0.95323, RMSEA $=0.000$ 
Variabel kepuasan pasien (Y1) diukur dengan 5 indikator pertanyaan yaitu Y1_1 sampai dengan Y1_5. Berdasarkan Gambar, dapat diketahui bahwa dari hasil pengujian loading factor menunjukkan bahwa Y1_1 sampai
Y1_5 memiliki nilai loading factor $>0,5$ dengan demikian indikator tersebut valid.

\section{Uji Validitas Loyalitas Pasien (Y2)}

Gambar 3

Pengujian Loading Factor Loyalitas Pasien (Y2)

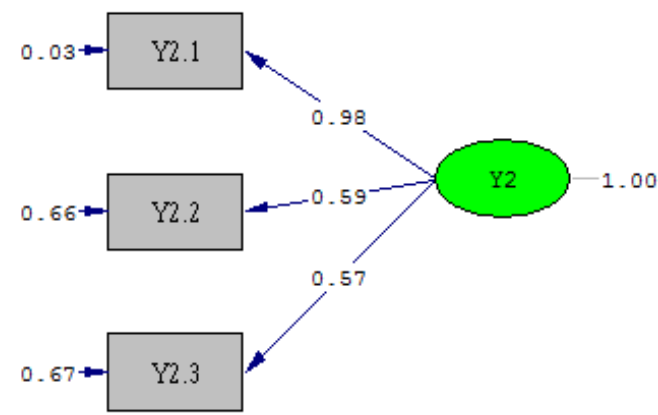

Chi-Square $=0.00, \mathrm{df}=0, \mathrm{P}-\mathrm{value}=1.00000, \mathrm{RMSEA}=0.000$

Variabel kepuasan pasien (Y1)

diukur dengan 5 indikator pertanyaan yaitu Y2_1 sampai dengan Y2_3. Berdasarkan Gambar, dapat diketahui bahwa dari hasil pengujian loading factor menunjukkan bahwa Y2_1 sampai Y2_3 memiliki nilai loading factor $>0,5$ dengan demikian indikator tersebut valid.

Tabel 3

Uji reliabilitas

\begin{tabular}{|c|c|c|c|c|c|}
\hline Variabel & Indikator & S.Load & S. Load $^{2}$ & 1 - S.Load & $\begin{array}{l}\text { CR }=\sum \text { s.load }{ }^{2} / \sum \\
\text { s.load }{ }^{2}+\sum\left(1-\varepsilon^{j}\right)\end{array}$ \\
\hline \multirow{10}{*}{$\begin{array}{l}\text { Kualitas } \\
\text { pelayanan } \\
(\mathrm{X})\end{array}$} & X1_1 & 0,63 & 0,40 & 0,60 & \multirow{10}{*}{0,795} \\
\hline & X1_2 & 0,73 & 0,53 & 0,47 & \\
\hline & X1_3 & 0,62 & 0,39 & 0,61 & \\
\hline & X1_4 & 0,65 & 0,42 & 0,58 & \\
\hline & X1_5 & 0,78 & 0,61 & 0,39 & \\
\hline & X1_6 & 0,66 & 0,44 & 0,56 & \\
\hline & $\mathrm{X} 1 \_7$ & 0,75 & 0,56 & 0,44 & \\
\hline & $\mathrm{X} 1 \_8$ & 0,67 & 0,45 & 0,55 & \\
\hline & X1_9 & 0,70 & 0,49 & 0,51 & \\
\hline & X1_10 & 0,69 & 0,48 & 0,52 & \\
\hline \multirow{3}{*}{$\begin{array}{l}\text { Kepuasan } \\
\text { Pasien (Y1) }\end{array}$} & Y1_1 & 0,67 & 0,45 & 0,55 & \multirow[b]{3}{*}{0,778} \\
\hline & Y1_2 & 0,64 & 0,41 & 0,59 & \\
\hline & Y1_3 & 0,68 & 0,46 & 0,54 & \\
\hline
\end{tabular}




\begin{tabular}{|l|l|l|l|l|l|}
\hline & Y1_4 & 0,79 & 0,62 & 0,38 & \multirow{}{*}{} \\
\cline { 2 - 5 } & Y1_5 & 0,56 & 0,31 & 0,69 & \\
\hline \multirow{2}{*}{$\begin{array}{l}\text { Loyalitas } \\
\text { Pasien (Y2) }\end{array}$} & Y2_1 & 0,85 & 0,72 & 0,28 & \multirow{3}{*}{$\mathbf{0 , 7 8 3}$} \\
\cline { 2 - 5 } & Y2_2 & 0,67 & 0,45 & 0,55 & \\
\cline { 2 - 5 } & Y2_3 & 0,62 & 0,38 & 0,62 & \\
\hline
\end{tabular}

Sumber : hasil olahan data penelitian, 2017

Berdasarkan tabel 3 menunjukkan bahwa, hasil perhitungan nilai $\mathrm{CR} \geq 0,70$ sehingga dapat disimpulkan bahwa seluruh konstruk pada full model loading factor untuk kualitas pelayanan, kepuasan pasien

dan loyalitas pasien dalam penelitian ini dalah dapat diterima dan reliable.

\section{Analisis Full Model}

Analisis Full Model Tanpa Modifikasi

\section{Gambar 4}

\section{Loading Factor Full Model}

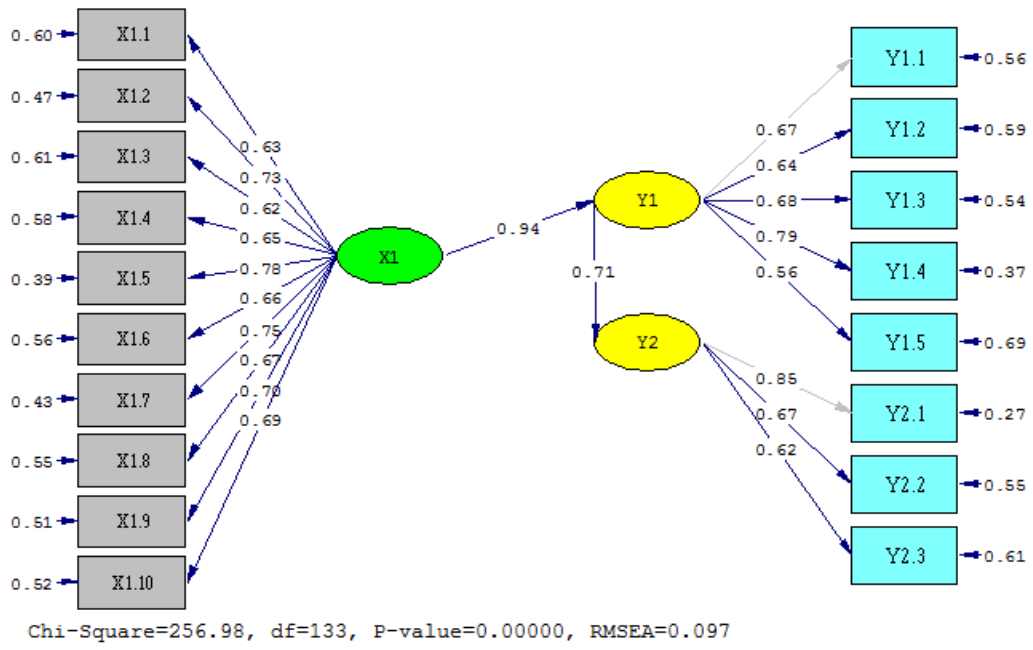

Menguji kelayakan model secara keseluruhan (full model) dilakukan dengan memperhatikan hasil perhitungan goodness of fit statistic dengan software LISREL 8,70 seperti tabel berikut:

Tabel 4

Goodness Of Fit Index

\begin{tabular}{|l|l|l|l|l|l|}
\hline No & Goodness Of Fit & Nilai & Cut Off Value (Nilai Batas) & Kriteria & \multirow{2}{*}{ Keterangan } \\
& & & & & \\
\hline 1. & $\mathrm{X}^{2}$ Chi-square & 256,98 & $>\alpha, \mathrm{df}$ & Good Fit & Tidak fit \\
\hline 2. & GFI & 0.78 & $\geq 0,90$ & Good Fit & Tidak fit \\
\hline 3. & AGFI & 0.71 & $\geq 0,90$ & Good Fit & Tidak fit \\
\hline 4. & CFI & 0.95 & $\geq 0,95$ & Good Fit & Good fit \\
\hline 5. & RMSEA & 0.097 & $\leq 0,08$ & Good Fit & Tidak fit \\
\hline
\end{tabular}

Sumber : Hasil Olah Data Penelitian, 2017

Berdasarkan tabel 4 hasil uji kelayakan model dari Goodness Of Fit Index menunjukkan CFI $(0,95)$ good fit dan sementara model yang lainnya tidak fit atau

tidak cocok dengan ketentuan dari goodnes of fit, sehingga perlu dilakukan modifikasi model untuk mendapatkan hasil yang sesuai dengan goodnes of fit dan adanya saran dari 
LISREL yang menunjukkan hasil kovarians $\mathrm{X} 1.1$ dan Y1.1, X1_1 dan Y1_4, X1_5 dan $\mathrm{Y} 1 \_3, \mathrm{X} 1 \_7$ dan $\mathrm{Y} 1 \_4, \mathrm{X} 1 \_8$ dan $\mathrm{X} 1 \_3$,
X1_9 dan X1_7, X1_10 dan X1_7, X1_10 dan X1_9.

Analisis Full Model Dengan Modifikasi Pertama

Gambar 5

Loading Factor Full Model Modifikasi Pertama

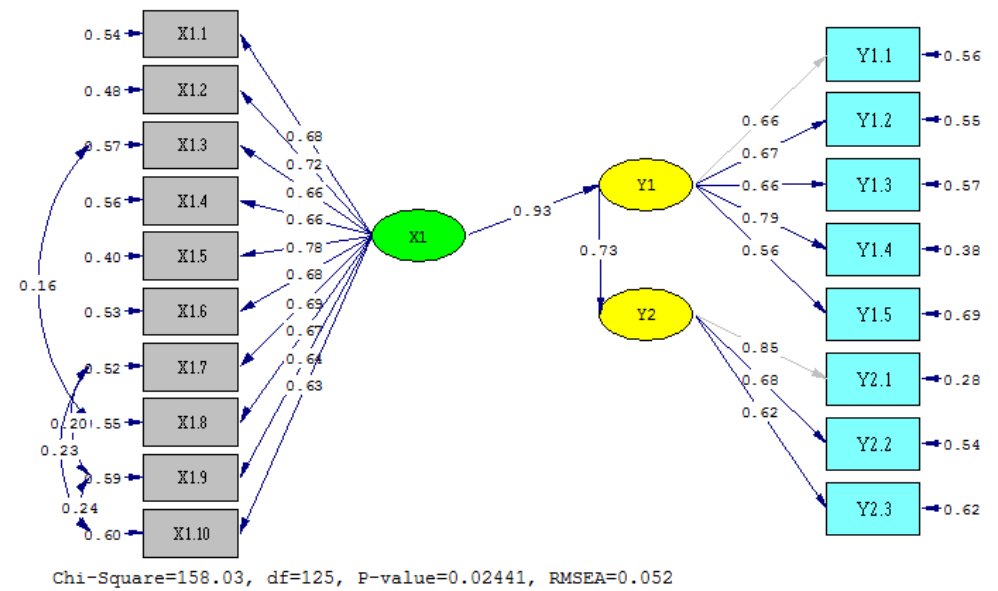

Menguji kelayakan model secara keseluruhan (full model) dilakukan dengan of fit statistic dengan software LISREL 8,70 seperti tabel berikut:

memperhatikan hasil perhitungan goodness

Tabel 5

Goodness Of Fit index

\begin{tabular}{|l|l|l|c|l|l|}
\hline No & Goodness Of Fit & Nilai & $\begin{array}{l}\text { Cut Off Value } \\
\text { (Nilai Batas) }\end{array}$ & Kriteria & Keterangan \\
\hline 1. & X $^{2}$ Chi-square & 158,03 & $>\alpha, \mathrm{df}$ & Good Fit & Good fit \\
\hline 2. & GFI & 0.85 & $\geq 0,90$ & Good Fit & Tidak fit \\
\hline 3. & AGFI & 0.79 & $\geq 0,90$ & Good Fit & Tidak fit \\
\hline 4. & CFI & 0.98 & $\geq 0,95$ & Good Fit & Good fit \\
\hline 5. & RMSEA & 0.052 & $\leq 0,08$ & Good Fit & Good fit \\
\hline
\end{tabular}

Sumber : Hasil Olah Data Penelitian, 2017

Berdasarkan tabel 5 hasil uji kelayakan model dari Goodness Of Fit Index menunjukkan CFI $(0,98)$, serta RMSEA (0.052) good fit, sementara model yang lainnya tidak fit atau tidak cocok dengan ketentuan dari goodnes of fit, sehingga perlu dilakukan modifikasi model untuk mendapatkan hasil yang sesuai dengan goodnes of fit dan adanya saran dari LISREL yang menunjukkan hasil kovarians X1_9 dan $\mathrm{X} 1 \_8$

Analisis Full Model Dengan Modifikasi Kedua 
Gambar 6

Loading Factor Full Model Modifikasi Kedua

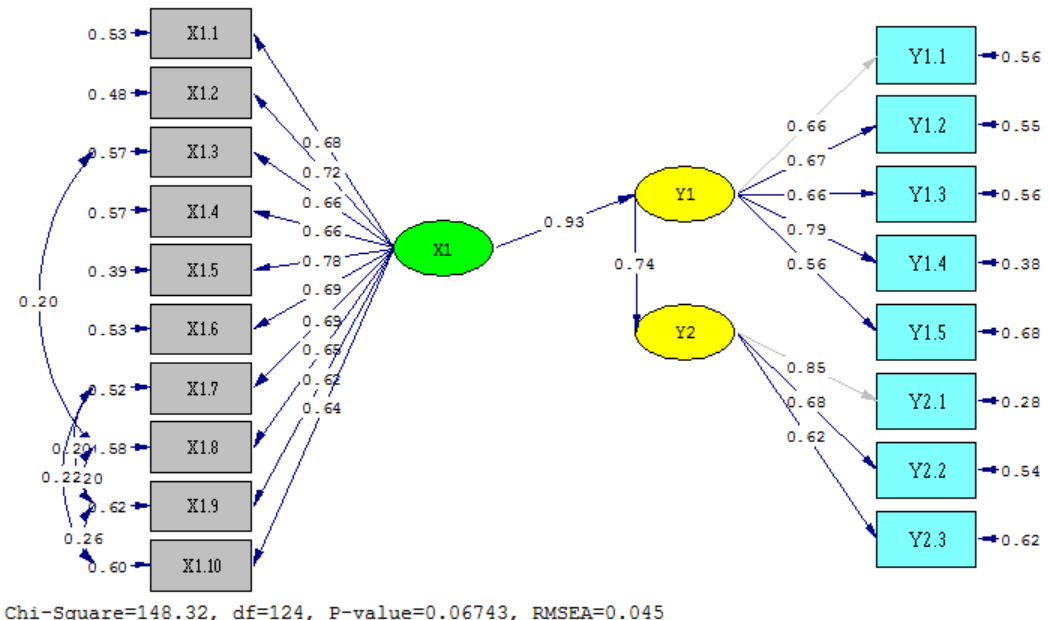

Menguji kelayakan model secara keseluruhan (full model) dilakukan dengan memperhatikan hasil perhitungan goodness of fit statistic dengan software LISREL 8,70 seperti tabel berikut:

Tabel 6

Goodness Of Fit index

\begin{tabular}{|l|l|l|l|l|l|}
\hline No & Goodness Of Fit & Nilai & $\begin{array}{l}\text { Cut Off Value } \\
\text { (Nilai Batas) }\end{array}$ & Kriteria & Keterangan \\
\hline 1. & X $^{2}$ Chi-square & 148,32 & $>\alpha, \mathrm{df}$ & Good Fit & Good fit \\
\hline 2. & GFI & 0.86 & $\geq 0,90$ & Good Fit & Tidak fit \\
\hline 3. & AGFI & 0.80 & $\geq 0,90$ & Good Fit & Tidak fit \\
\hline 4. & CFI & 0.99 & $\geq 0,95$ & Good Fit & Good fit \\
\hline 5. & RMSEA & 0.045 & $\leq 0,08$ & Good Fit & Good fit \\
\hline
\end{tabular}

Sumber : Hasil Olah Data Penelitian, 2017

Berdasarkan tabel 6 menunjukkan bahwa SEM yang digunakan untuk menguji hubungan antar variabel dalam menunjukkan bahwa model ini dapat diterima. Tingkat signifikan untuk uji hepotesis perbedaan (chi square) sebesar 148,32. Uji terhadap dua variabel uji yang dibawah cut off value namun tidak terlalu signifikan perbedaanya yaitu GFI dan AGFI menunjukkan tingkat penerimaan yang marginal atau tidak fit, sementara CFI dan RMSEA menunjukkan bahwa model ini sesuai (fit) karena hampir semua cut off value indikator uji dapat terpenuhi, dan menurut estimasi LISREL tidak perlu untuk melakukan uji kecocokan model respesifikasi karena konvarians error sudah tidak ada lagi.

Hasil Uji Hipotesis

\section{Gambar 7}




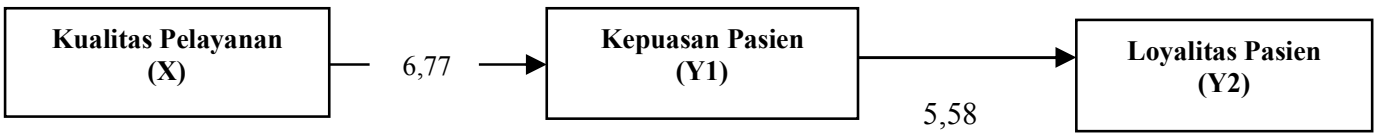

Sumber: Hasil Data Olah Penelitian, 2017

Tabel 7

Hasil Uji Hipotesis

\begin{tabular}{|c|c|c|c|}
\hline Variabel & Pengaruh & t-value & Hasil \\
\hline $\mathrm{X} \longrightarrow \mathrm{Y} 1$ & $93 \%$ & 6,77 & Positif signifikan \\
\hline $\mathrm{Y} 1 \longrightarrow \mathrm{Y} 2$ & $74 \%$ & 5,58 & Positif signifikan \\
\hline
\end{tabular}

Sumber: Hasil Olah Data Penelitian, 2017

Berdasarkan gambar 7 dan tabel 7 dapat dilihat bahwa $\mathrm{X}$ berpengaruh positif sebesar 93\% dan signifikan terhadap Y1 yang ditujukkan dengan t-value sebesar 6,77 (diatas 1,96). Y1 berpengaruh positif sebesar $74 \%$ dan signifikan terhadap Y2 yang ditujukkan dengan t-value sebesar 5,58 (diatas 1,96).

\section{PEMBAHASAN / DISCUSSION}

Berdasarkan hasil penelitian ini diketahui bahwa ada pengaruh positif kualitas pelayanan terhadap kepuasan pasien dan kepuasan pasien terhadap loyalitas pasien rumah sakit muhammadiyah Palembang. Hal ini dapat ditunjukkan melalui hasil pengujian t-value Full Model, pada hasil pengujian tersebut memperlihatkan variabel kualitas pelayanan memiliki pengaruh positif terhadap kapuasan pasien dan kepuasan pasien memiliki pengaruh positif terhadap loyalitas pasien rumah sakit Muhammadiyah palembang. Hal ini dapat ditujukkan sebagai berikut:

\section{Pengaruh Kualitas Pelayanan Terhadap Kepuasan Pasien Rumah Sakit Muhammadiyah Palembang}

Kualitas pelayanan merupakan ukuran sejauh mana suatu pelayanan yang diberikan dapat memenuhi harapan pelanggan. Indikator dari kualiitas pelayanan dalam penelitian ini yaitu: ruang tunggu, peralatan diagnosis akurat, janji konsultasi, pelayanan, informasi, kesopanan, kepercayaan, sabar dan perhatian.

Masing-masing indikator ini sangat memiliki pengaruh signifikan terhadap kepuasan pasien rumah sakit muhammadiyah palembang.

Mengenai bukti fisik (X1) di rumah sakit Muhammadiyah Palembang dari hasil jawaban responden pada penelitian ini masih terdapat pasien rumah sakit Muhammadiyah Palembang yang menyatakan kurang puas terhadap terhadap bukti fisik rumah sakit Muhammadiyah Palembang. Faktor yang menyebabkan kurang puasnya para responden ialah kurang lengkapnya peralatan medis yang ada di rumah sakit Muhammadiyah Palembang.

Oleh karena itu rumah sakit Muhammadiyah Palembang perlu melengkapi peralatan medisnya agar supaya pasien tidak beralih ke rumah sakit lain untuk melakukan perobatan dan para pasien merasa puas dengan peralatan yang sudah dilengkapi.

Kehandalan (X2), para responden dalam penelitian ini mmengeluhkan lamanya menunggu dokter di rumah sakit Muhammadiyah Palembang ketika akan 
Balance Vol. XV No. 2 | Juli 2018

berkonsultasi. Kondisi ini berdampak pada kepuasan pasien di rumah sakit Muhammadiyah Palembang, maka hal ini rumah sakit Muhammadiyah Palembang harus mengarahkan tenaga medis di rumah sakit Muhammadiyah Palembang untuk dating tepat waktu, agar para pasien tidak terlalu lama menunggu ketika akan berkonsultasi sehingga pasien merasa puas.

Daya tanggap (X3) di rumah sakit Muhammadiyah Palembang, para responden dalam penelitian ini masih mengeluhkan lambatnya pelayanan di rumah sakit Muhammadiyah Palembang, seperti kurang nya respon para perawat saat di panggil pasien untuk melihat kondisinya, sehingga kondisi seperti ini berdampak pada tingkat kepuasan pasien.

Jaminan (X4) rumah sakit Muhammadiyah Palembang harus melakukan perbaikan, berdasarkan jawaban responden dalam penelitian ini mengeluhkan kurang sabarnya perawat dan para petugas keamanan dalam menghadapi pasien sehingga para pasien merasa enggan dan kurang nyaman terhadap perawat dan para petugas keamanan, rumah dalam hal ini rumah sakit Muhammadiyah Palembang harus mengarahkan kembali agar para pegawainya lebih sabar ketika mengahadapi pasein yang mau berobat di rumah sakit Muhmmadiyah Palembang.

Empati (X5) di rumah sakit Muhammadiyah Palembang, para responden dalam penelitian ini mengeluhkan kurangnya perhatian dari para perawat rumah sakit Muhammadiyah Palembang terhadap para pasiennya. Dalam hal ini pimpinan rumah sakit Muhammadiyah Palembang harus mengarahkan kembali para perawatnya agar lebih perhatian terhadap para pasien, sehingga pasien merasa nyaman dan puas ketika berobat di rumah sakit Muhammadiyah Palembang.

\section{Pengaruh kepuasan pasien terhadap loyalitas pasien rumah sakit Muhammadiyah Palembang}

Kepuasan pasien adalah Respon pasien rumah sakit muhammadiyah palembang terhadap evaluasi ketidaksesuaian (disconfirmation) yang dirasakan antara harapan sebelumnya (norma kinerja lainnya) dan kinerja actual produk atau jasa yang dirasakan setelah pemakaian. Indikator dari kepuasan pasien yaitu: kelengkapan fasilitas sudah memadai, dokter yang melayani adalah dokter spesialis, dokter/perawat melayani dengan cepat dan tanggap, dokter/perawat melayani pasien dengan profesional, dan dokter/perawat mendengarkan keluhan pasien.

Masing-masing indikator ini sangat memiliki pengaruh signifikan terhadap loyalitas pasien rumah sakit muhammadiyah palembang. Apabila kepuasan tinggi maka loyalitas pasien juga akan meningkat. Pelanggan atau pasien yang puas akan memberikan dasar yang baik bagi pembelian ulang dan terciptanya loyalitas pasien.

\section{KESIMPULAN / CONCLUSSION}

Kesimpulan

1. Kualitas pelayanan berpengaruh signifikan terhadap kepuasan pasien yang diperoleh nilai t-value sebesar 6,77 sehingga $\mathrm{H}_{0}$ ditolak dikarenakan $6,77>$ 1,96. Artinya kualitas pelayanan mempunyai pengaruh yang signifikan terhadap kepuasan pasien rumah sakit muhammadiyah palembang. Kualitas pelayanan berpengaruh positif karena ruang tunggu, peralatan, diagnosis akurat, janji konsultasi, pelayanan, informasi, kesopanan, kepercayaan, sabar, dan perhatian sudah cukup baik yang dilakukan rumah sakit Muhammadiyah Palembang dan membuat pasien merasakan kepuasan tentang pelayanan 
yang diberikan rumah sakit Muhammadiyah Palembang.

2. Kepuasan pasien berpengaruh signifikan terhadap loyalitas pasien yang diperoleh nilai t-value sebesar 5,58 sehingga $\mathrm{H}_{0}$ ditolak dikarenakan 5,58 > 1,96. Artinya dapat disimpulkan bahwa kepuasan pasien berpengaruh signifikan terhadap loyalitas pasien, karena dokter spesialis, dokter/perawat melayani dengan cepat dan tanggap, dokter/perawat melayani pasien dengan professional dan dokter/perawat mendengarkan keluhan pasien yang sudah puas yang diberikan rumah sakit Muhammadiyah Palembang sehingga pasien akan menjadi loyal kepada rumah sakit Muhammadiyah Palembang.

Saran

Rumah Sakit Muhammadiyah Palembang harus memperhatikan kualitas pelayanan khususnya melengkapi peralatan medis, jadwal konsultasi yang kurang tepat, pelayanan dokter/perawat kurang cepat dan tanggap, serta perawat yang kurang sabar dan perhatian dalam menghadapi pasien. Karena apabila kualitas pelayanan sudah diperhatikan dengan baik maka pasien akan merasakan kepuasannya terpenuhi sehingga akan meningkatkan loyalitas pasien ke rumah sakit Muhammadiyah Palembang.

\section{DAFTAR PUSTAKA / BIBLIOGRAPHY}

Habibaturrahmah, Diah Isnaini Asiati. 2011. Pengaruh Kualitas Pelayanan Terhadap Kepuasan Pasien Rumah Sakit Muhammadiyah Palembang

Huriyati,Ratih. 2009. Bauran Pemasaran dan Loyalitas Konsumen. Bandung : Alfabeta

Khotler Amstrong. 2008. Manajemen Pemasaran. Jakarta : Erlangga

Khotler, Keller. 2009. Manajemen Pemasaran. Jakarta : Erlangga

M. Rofik. 2015. Pengaruh Kualitas Pelayanan Terhadap Kepuasan Pasien Rumah Sakit Muhammadiyah Palembang

Tjiptono, Fandy. 2008. Strategi Pemasaran. Jakarta : Pustaka 